\title{
Dysfunctional sexual
} profiles and treatments

Received: 06 June, 2020

Accepted: 02 October, 2020

Published: 03 October, 2020

*Corresponding author: Dr. Giulio Perrotta, Psychologist sp.ed Strategic Psychotherapist, Forensic Criminologist, Jurist sp.ing SSPL, Lecturer, Essayist, Italy, E-mail: giuliosr1984@hotmail.it

https://www.peertechz.com

\section{Check for updates}

\section{Giulio Perrotta* \\ Psychologist sp.ed Strategic Psychotherapist, Forensic Criminologist, Jurist sp.ing SSPL, Lecturer, \\ Essayist, Italy}

\begin{abstract}
This work focuses on the theme of "dysfunctional sexual behaviors" and in particular on clinical, psychopathological, and anatomy physiological elements, to fully understand the different grades of the behavior under consideration: hypersexuality, persistent sexual arousal disorder, and sex addiction. The work is completed with an analysis of the etiological elements and the best treatments, emphasizing the clinical importance of the use of pornography in sexual addictions.
\end{abstract}

\section{Contents of the manuscript}

\section{Introduction, definition and clinical contexts}

Dysfunctional sexual behavior is a way of acting of the person, in relationship and interaction with the surrounding environment, which experiences an obsessive (and therefore pathological) need to think about sex, implementing psychological behaviors aimed at carrying out intense sexual activity, losing control over the impulses and limits socially imposed by the factual circumstances. In general, "being addicted" means having lost and not being able to regain control over appetitive behavior, that is, the desire to have and consume something. Therefore, if a control situation occurs when the individual deems the condition in which he/she consumes an object or engages in behavior, regardless of how intense, enduring or risky this involvement is, control is lost when the behavior is repeated despite a general dissatisfaction, or despite damage to the rest of the individual's life, which makes him undesirable. It is not so much the behavior that is pathological but the absence of control over the purposes of gratification that the individual wants to achieve. Behavior that no longer satisfies normality should die out, even if it was gratifying before, because it ceased to be so. If this does not occur, and the person cannot fail to think of it as rewarding despite the disappointment of the drink, control has been lost. In the same way, if the person cannot organize his behavior to insert it in his life when and how he wants (that is free), he ends up sacrificing the rest of his life to the desire to implement the behavior whenever it comes out (that is, he becomes his slave). Thus it also becomes increasingly difficult to obtain resources to support the behavior itself (for example economic), and even if the behavior itself remains rewarding there is no longer general satisfaction, and such gratification is increasingly difficult due to the inability to manage the desire. It is therefore a real addiction like any other compulsive substance or behavior and has its specific gradation, based on the severity of the pathological condition; in fact, the three forms are distinguished: hypersexuality, persistent sexual arousal disorder and sex addiction [1].

Only recently, hypersexuality disorder found a classification within the International Classification of Diseases for Mortality and Morbidity Statistics (ICD-11) [2] with the code 6C72, as the category separated from paraphilias within the impulse control. According to the definition of the World Health Organization (WHO) [3], the compulsive sexual behavior disorder is characterized by a persistent pattern of failure to control intense, repetitive sexual impulses or urges resulting in repetitive sexual behavior. Symptoms may include repetitive 
sexual activities becoming a central focus of the person's life to the point of neglecting health and personal care or other interests, activities, and responsibilities; numerous unsuccessful efforts to significantly reduce repetitive sexual behavior, and continued repetitive sexual behavior despite adverse consequences or deriving little or no satisfaction from it. The pattern of failure to control intense, sexual impulses or urges and resulting repetitive sexual behavior is manifested over an extended period (e.g., 6 months or more), and causes marked distress or significant impairment in personal, family, social, educational, occupational, or other important areas of functioning. Distress that is entirely related to moral judgments and disapproval about sexual impulses, urges, or behaviours is not sufficient to meet this requirement. Despite repeated attempts to reduce the frequency of dysfunctional sexual behavior, the person suffering from hypersexuality cannot control his compulsions, and based on the severity of his disorder, he can present evident anxious symptoms, mood swings, unmotivated aggression, hypermanicity, obsessiveness and compulsiveness [4].

The fifth updated version of the Diagnostic and Statistical Manual of Mental Disorders drafted by the American Psychiatric Association (Diagnostic Manual of Mental Disorder, DSM-5) [5] however does not include the hypersexuality disorder in the classification of mental diseases, although the two categories are present for sexual dysfunctions related to difficulty in reaching orgasm or sexual arousal and paraphilic disorders [5]. The scientific community has much debated on the danger of excessively psychiatrizing individual behaviors and attitudes of subjects who by nature have a higher basic sexual libido than the average, or who live in a socio-cultural context in which such hypersexualized behaviors are commonly accepted. Similarly, the issue of differential diagnosis remains controversial, so that hypersexuality disorder, manifesting itself very often in conjunction with other psychiatric disorders such as bipolar disorder or depressive syndromes, should not be diagnosed as an independent disorder, but as a secondary symptom of the mood disorder. Experts who, on the contrary, claim that it exists, describe hypersexuality as an effective addiction, like others like alcoholism and drug addiction. The act, in this case the sexual one, would be used as the only pathological modality to manage stress or personality and mood disorders [4].

From a symptomatic point of view, Hypersexuality, therefore, manifests itself in the person's attitude to losing the commonly accepted inhibition, involuntarily preferring a conduct oriented in the continuous manifestation of seductive acts, provocative and eager for sexual approaches. It is a strong accentuation and exaltation of sexual instincts and impulses, which push the subject to always show interest in physical contact or a sexual approach. However, this attitude is not always aimed at achieving sexual intercourse; often it represents a way to attract attention and to give vent to those internal sexual drives that otherwise we will not find a way to free ourselves. It is customary for these subjects to compulsively and hypermaniacally practice the masturbatory art of their sexual genitalia. In particular, masturbation is a particular case because more than a perversion it represents a substitute activity, which can take on the characteristics of an addiction through a way that makes it particularly rewarding, that is usually pornography, or voyeurism, that is, pornography "Live" practiced for a fee or by witnessing relationships with others, or clandestinely (spying on people intent on sexual activities). The person who habitually masturbates is usually beset by the discomfort of not being able to have the object of ideal desire, and of having to settle for masturbation. Sometimes, on the other hand, the person ends up isolating themselves socially or developing a disability in social relationships because their sexuality is taken hostage by masturbation. Otherwise, masturbation becomes pathological because the increase in frequency corresponds to a lower satisfaction, sought angrily or anxiously without success, or corresponds to a demoralizing and embarrassing condition for the person. Pathological masturbation is commonly called "compulsive" although in reality this creates the incorrect idea that represents a variant of obsessive-compulsive disorder. Sexual fantasy differs from obsession in that it is sought, produced and nourished as a means of gratification, and masturbatory activity is not practiced against one's will at the moment, but if ever against one's general intentions. At this level of dysfunctionality, however, paraphilic tendencies can coexist but represent the background of this condition. For example, a person with sexual hyperactivity can choose the pornographic material he prefers or the paid partners he prefers, while the sexual employee ends up spending his time in this research to the point of no longer being available (because he is no longer able to work or devote himself to social life) of large resources, and therefore perhaps adapts to the first things it finds, also accepting risks (hygienic and infectious, or environmental), to consume immediately [1]

When hypersexuality tends to become chronic, there will be talk of a real disorder, the second level by gravity: Persistent Sexual Arousal Disorder (PSAD). The continuous sexual excitement pushes the person to compulsively seek circumstances and events that have a sexual connotation; therefore hypersexuality becomes the starting point of this disorder. To satisfy one's drive, the subject may experience an increasingly intense search for sexual intercourse tending to be obscene or perverse. For this reason, these aspects should be contextualized in an area of psychological-psychiatric distress; however, the subject still manages to maintain a semblance of normality, binding these behaviors only to the sphere of his own emotional and sexual sphere, limiting the deterioration of human relationships and the typical stigma of a man sexuallyoriented towards a fixation or an addiction. The subjects in question are often victims of paraphilias, who must represent and live in their emotional and sentimental life [1].

When the need to feel uninhibited and sexually free becomes a constant and uncontrollable need to perform sexual acts, continuous excitement becomes a real addiction: Sex-addiction. It represents the last level by gravity of dysfunctional sexual behavior and is often accompanied by the need to perform sexual acts with people or objects by creating one or more paraphilias. The purpose is the realization of pleasure and often the consequences of one's actions, even if known to the subject, are underestimated or not duly taken into consideration,

Citation: Perrotta G (2020) Dysfunctional sexual behaviors: definition, clinical contexts, neurobiological profiles and treatments. Int J Sex Reprod Health Care 3(1) 
because the tension they would cause would frustrate the sexual energy that is ready to let off steam [6]. Sex addiction characterizes a persistent pattern of failure to control intense [and] repetitive sexual impulses or urges, resulting in repetitive sexual behavior over an extended period that causes significant distress or impairment in personal, family, social, educational, occupational, or other important areas of functioning [7]. Sex-addiction, in the past, in the medical field, was known with the terms "Nymphomania" (referring to women) and "Satirism or Satiriasis" (referring to men), since in Greek mythology the Nymphs were defined in their nature within the sphere of the divine power of Aidòs, therefore to privacy and amazement in the face of what is immaculate and therefore silent and they were represented as beautiful eternally young girls, capable of attracting men and heroes, while the Satyrs were generally depicted as bearded humans with goat or horse ears, horns, tail, and legs, dedicated to wine, to play and dance with the Nymphs, in the company of a showy sexual erection [1]. In the recent past, the condition was also described as hypersexuality, hypersexual behavior, sexual impulsivity, and compulsive sexual behavior; even more recently, compulsive sexual behavior has been proposed as an impulse control disorder for inclusion in ICD-11, with Internet field trials and clinical studies planned to test its validity [7]. Today these two terms have fallen into disuse. Pathological dependence is in some cases progressive, increasing in intensity with the concomitant occurrence of a form of sexual saturation. Here the subject is no longer able to distinguish socially accepted limits and his dependence completely conditions him, in all spheres of his existence, from personal to family, from work to social. Paraphilias become a way of experiencing sexuality like any other and seek pleasure concomitantly with the use of pornography. Among the consequences of this aggravation we can mention the following clinical signs: physical and mental stress caused by the frenetic, obsessive, compulsive and obsessive search for sexually-oriented sources; deterioration of social relationships; decrease in short-term memory and synthesis; cognitive opacity and decreased cognitive skills such as intuition, abstraction, synthesis, creativity and concentration; search for sexual pleasure in any context without evaluating the consequences of one's actions (also with judicial implications); decreased physical performance and chronic fatigue; altered circadian rhythm of sleep; increased anxious states; explosive aggression; persistent sense of frustration; perennial dissatisfaction; sense of apathy and disappointment when the sexual act is completed; dedication to the daily search for sexually stimulating situations, for most of the hours of the day; restlessness; social isolation; attractive and affective saturation with difficulty falling in love; variation of the usual sexual relationships in which the subject tries to recreate with his partner (even occasional) one or more obscene patterns, desubjecting people. In cases, this condition is often in comorbidity with other psychopathological disorders such as depression, mood disorders, conduct disorders, sexual disorders, other forms of addiction (behavioral and substance), sleep-wakefulness disorders, and personality disorders [1].

Concerning the clinical contexts, however, always starting from the difference between hypersexuality, persistent sexual arousal disorder and sex-addiction, the pathological condition tends to be distinguished based on the severity of the symptoms narrated in the anamnesis; therefore, hypersexuality (which is the starting point of the dysfunctional condition, about sexual behavior) may be a specific symptom of one of these four diagnostic hypotheses [7].

1) "Hypersexuality" as a source of psychosocial distress, since the activity carried out by the person, although considered normal, is represented on average higher than the social and clinical standards [7]. In this context, the search for asexuality more linked to the pornographic and paraphilic sphere represents a simple and different way of experiencing sexuality, even as a couple, without compromising the other social areas of the person (family, emotional, sentimental, working), while there is an underlying ego-dystonic condition that disturbs the person, making him perceive his sexual hyperactivity as a pathological symptom [8] generating feelings of guilt and shame [9];

2) "Hypersexuality" as a symptom of a physical condition of medical interest, pre-existing to sexual conduct deemed dysfunctional (for example, dementia or brain tumor) [7];

3) "Hypersexuality" as a symptom of a psychic condition of medical interest, existing or concomitant or after sexual conduct deemed dysfunctional (for example, obsessivecompulsive disorder, manic disorder, or personality disorder) [7]. Compared to the symptoms described in the anamnesis, hegosynthesis represents the relevant clinical element that leads the diagnosis from a character and behavior disorder to a real personality disorder (for example, borderline personality disorder) [1].

4) "Hypersexuality" as a symptom of a specific psychological condition that tends to eroticization (in this case, reference is made to dysfunctional hypersexuality that will tend to chronicization, up to sexual behavioral dependence) [7].

\section{Neurobiological profiles}

Proponents of the "sexual addiction theory" identify the organic component of the pathology in the same physiological models of addictions to gambling, so an important dysfunction of the dopaminergic and serotonergic system would be the basis of compulsive and uncontrolled research sexual satisfaction. The dopamine neurotransmitter emitted by neurons located in the limbic system (nucleus accumbens and in general the ventral striatum) would be released in a dysregulated manner in subjects suffering from the disorder. This neurotransmitter has the function of urging the implementation of behaviors aimed at achieving pleasure, which also include those behaviors that guarantee survival in humans (search for food and water, reproductive behavior ...). Although not yet definitively validated by significant scientific research, scholars have also theorized the involvement in the etiology of hypersexuality of the neurotransmitter serotonergic, a neuronal hormone that makes you experience the feeling of happiness, satiety, and 
contentment. Starting from the serotonergic neurons located in the prefrontal cortex, the serotonergic afferents project onto the nucleus accumbens by modulating the production of dopamine and thus regulating voluntary inhibition and behavior control. In subjects suffering from diseases of impulse dysregulation and obsessive-compulsive disorder, this function would be affected $[10,11]$.

A recent research then hypothesized dysfunctional sexual behaviors as a real neuropsychiatric disorder: "Hypersexuality refers to abnormally increased or extreme involvement in any sexual activity. It is clinically challenging, presents trans-diagnostically and there is extensive medical literature addressing the nosology, pathogenesis, and neuropsychiatric aspects in this clinical syndrome. Classification includes deviant behaviors, diagnosable entities related to impulsivity, and obsessional phenomena. Some clinicians view an increase in sexual desire as 'normal' i.e. psychodynamic theorists consider it as ego defensive at times alleviating unconscious anxiety rooted in intrapsychic conflicts. We highlight hypersexuality as multi-dimensional involving an increase in sexual activity that is associated with distress and functional impairment. The etiology of hypersexuality is multi-factorial with differential diagnoses that include major psychiatric disorders (eg bipolar disorder), adverse effects of treatments (eg levodopa treatment), substance-induced disorders (eg amphetamine substance use), neuropathological disorders (eg frontal lobe syndrome), among others. Numerous neurotransmitters are implicated in its pathogenesis, with dopamine and noradrenaline playing a crucial role in the neural reward pathways and emotionallyregulated limbic system neural circuits. The management of hypersexuality is determined by the principle of de causa effects evanescent, if the causes are treated, the effect may disappear. We aim to review the role of pharmacological agents causing hypersexuality and centrally acting agents treating the associated underlying medical conditions. Bio-psycho-social determinants are pivotal in embracing the understanding and guiding management of this complex and multi-determined clinical syndrome" [12].

Finally, other scientific research suggests the possible involvement of the pituitary-hypothalamic-adrenal axis [13,14] and the nucleus frontostriatal [15], other research (especially French), on the other hand, is oriented on the link between dysfunctional sexual behaviors and oxytocin [15-17], even if the latter hypothesis has not yet been confirmed with certainty despite the important intuition. An oxytocin-based therapy (with nasal spray) could on this basis, if confirmed, an alternative and complementary therapy to the best protocols currently in use [18].

\section{Etiological and diagnostic profiles}

The underlying causes of these conditions are not yet fully known, even though the prevalent orientation in the literature is certainly multifactorial: genetic, neurobiological, hormonal, psychological, environmental [12]. But also specific pathological conditions, such as epilepsies $[19,20]$, dementia [21,22], obsessive-compulsive disorder [23] ADHD [24], impulse control disorder [25] and vascular diseases [26].
However, to distinguish dysfunctional conditions from normal sexual activity (albeit intense and prolific), some data must be taken into account in the patient's medical history [27].

A) The patient is disturbed by his sexual conduct and has a negative self-esteem;

B) The patient continuously searches for situations and people with a high sexual content;

C) The patient spends many hours a day on sex;

D) The patient presents paraphiliac behaviors in his clinical history;

E) The patient is unable to calm the sexual impulse, which is considered obsessive;

F) The patient, with his sexual conduct, has affected other spheres of his life, such as work, affective and family life;

G) The patient feels emotionally unstable when he does not perform sexual acts;

H) The patient compromises his human and social relationships due to his sexual conduct.

To facilitate this interpretation, however, standardized exams and tests have also been developed such as SAST (United States of America) and SESAMO (Italy); in particular, the latter abbreviation stands for Sexrelation Evaluation Schedule Assessment Monitoring, a psychodiagnostic test created in Italy, validated and standardized on the Italian population, which is based on a questionnaire through which it is possible to explore sexual and relational, regulatory aspects and dysfunctional, in single subjects or with couple life. The test consists of two questionnaires, a version intended for women and one for men, each of which is divided into three sections: the first section contains the items that explore the areas concerning the aspects of remote sexuality, the social, environmental and distinctive characteristics of the subject, as well as a medical history. This section is compiled by all the respondents who, at the end of this first part, will be directed to one of the two subsections based on their emotional-relational condition, defined as "single situation" or "couple situation"; the second section collects items whose areas of investigation are related to current sexuality and motivational aspects; this section is reserved for the situation of Single, meaning by this the non-presence of a stable sexual-affective relationship of the subject with a partner; the third section includes the areas that investigate the subject's current sexuality and the relationship aspects of the couple. This part is addressed to the dyadic situation, intended as the presence of a sexual affective relationship that has lasted for at least six months with a partner. After the end of the administration, no changes can be made to the contents of the questionnaire and the report, this is appropriate for ethical reasons but it is above all necessary for the validity in the expert field and the screening. The report consists of 9 sections, including personal and family data, 
the graph, the scoring, the critical traits, and the narrative report, to conclude with the parameters and the answers to the questionnaire [28].

\section{The use of pornography in sexual addictions}

Notoriously, pornography is the explicit representation of erotic and sexual subjects in various forms, from literature to painting, to cinematography and photography. Of Greek origin, this activity represents an art form, as every human being normally has erotic fantasies, that is, he uses the imagination to represent erotically exciting scenes, with no other purpose than excitement in itself: pornography is the concretization of these fantasies in images, drawings, writings, objects or other productions. Since many people have similar erotic fantasies, usually the pornographic material produced by a single person, with the scenes of his erotic imagination, is also exciting for many others. Although pornography has also been used as a simple ingredient in more complex artistic works, its main purpose is to induce a state of sexual arousal. There has always been debate about the changing boundary between art, eroticism, and pornography, which is generally not considered illegal in western legal systems, but in certain contexts it is (or has been) subject to censorship and its viewing is prohibited (especially to minors). The great availability of the public and the cost-effectiveness of the medium make the internet a widely used medium for the distribution and use of pornographic content materials. In fact, with the advent of the internet, especially for the diffusion of systems such as file sharing (file sharing) and video sharing (video sharing), pornography has become immediately and anonymously available everywhere and for anyone. The latest consequence of this phenomenon has, first of all, mitigated the general feeling of condemnation in the face of this form of expression, while on the other hand, it has facilitated the explosion or very wide diffusion of phenomena such as the "amateur" genre, consisting in the creation of photos and videos porn-erotic character portraying ordinary people (often the same authors as the product). In addition to file sharing, another main distribution channel for internet pornography is represented by paid sites, an increasingly lucrative activity for producers of professional material who are privileging the web over classic distribution channels such as newsstands, video stores and sex shops. Thanks to the network, what some authors call neo-porn is increasingly affirming, while the flash game for adults, or electronic games, are spreading, whose situations (although varying from comedy to fantasy) maintain a declaredly pornographic character. Thanks to the disclosure of paid and non-paid shows, through the webcam broadcast (very popular all over the web), it allows attending porn shows and communicating via chat with those who are performing at that time [29].

Recent scientific research on sexual addiction and pornography has found that:

1. The use of pornography among young people, who use it massively online, is connected to the decrease in sexual desire and premature ejaculation, as well as in some cases to social anxiety disorders, depression, DOC, and ADHD [30-32].

2. There is a clear neurobiological difference between "sexual employees" and "porn addicts": if the former has a ventral hypoactivity, the latter instead are characterized by greater ventral reactivity for erotic signals and rewards without hypoactivity of the reward circuits. This would suggest that employees need interpersonal physical contact, while the latter tend to solitary activity $[33,34]$. Also, drug addicts exhibit greater disorganization of the white matter of the prefrontal cortex [35].

3. Porn addiction, although distinct neurobiologically from sexual addiction, is still a form of behavioral addiction and this dysfunctionality favors an aggravation of the person's psychopathological condition, directly and indirectly involving a neurobiological modification at the level of desensitization to functional sexual stimulus, hypersensitization to stimulus sexual dysfunction, a marked level of stress capable of affecting the hormonal values of the pituitary-hypothalamic-adrenal axis and hypofrontality of the prefrontal circuits [36].

4. The low tolerance of pornography consumption was confirmed by an fMRI study which found a lower presence of gray matter in the reward system (dorsal striatum) related to the quantity of pornography consumed. He also found that increased use of pornography is correlated with less activation of the reward circuit while briefly watching sexual photos. Researchers believe their results indicated desensitization and possibly tolerance, which is the need for more stimulation to achieve the same level of arousal. Furthermore, signals of lower potential have been found in Putamen in porndependent subjects [37].

5. Contrary to what one might think, porn addicts do not have a high sexual desire and the masturbatory practice associated with viewing pornographic material decreases the desire also favoring premature ejaculation, as the subject feels more comfortable in solo activity. Therefore individuals with greater reactivity to porn prefer to perform solitary sexual acts than shared with a real person $[38,39]$.

6. The sudden suspension of porn addiction causes negative effects in mood, excitement, and relational and sexual satisfaction $[40,41]$.

7. The massive use of pornography facilitates the onset of psychosocial disorders and relationship difficulties [42].

8. The neural networks involved in sexual behavior are similar to those involved in processing other rewards, including addictions. The overlap of the classic reward brain areas involved in sexual arousal, love, and attachment has been clarified with the ventral tegmental area, the nucleus accumbens, the 
amygdala, the basal ganglia, the prefrontal cortex and the cortex orbitofrontal being the common substrate. A model called the "reward deficit syndrome model" (RDS) has been implicated in pornography addiction and implies a genetic dissatisfaction or impairment of brain reward which results in an aberrant pleasure in seeking behaviors that include drugs, overeating, sexuality games, gambling, and other behaviors. Thus, the continuous release of dopamine into the reward system was confirmed when an individual compulsively and chronically watches pornography stimulates neuroplastic changes that reinforce the experience. These neuroplastic changes build brain maps for sexual arousal. All forms of addiction are known to involve the dopamine mesolimbic pathway (DA), which originates in the ventral tegmental area (VTA) and is projected into the nucleus accumbens (NAcc) which forms the reward circuit in addiction. This circuit has been implicated in the pleasure, empowerment, learning, rewarding, and impulsiveness observed in addictions. The mesolimbic pathway of dopamine is linked to three brain regions to form extended reward circuits called addictive reward systems. The structures involved are the amygdala that codes for positive and negative emotions, fear and emotional memory, the hippocampus that deals with the processing and recovery of long-term memories, and the frontal cortex that coordinates and determines the behavior of addiction. Different classes of psychoactive drugs can activate the reward system in different ways, however, the universal result is a flow of dopamine into the nucleus accumbens (the reward center). This results in a positive acute reinforcement of the behavior that initiated the flood and addiction-related learning associations. Once the dopamine flood has finished its course, there is activation of the extended amygdala, an area associated with pain processing and fear conditioning. This leads to the activation of brain stress systems and the dysregulation of anti-stress systems with a reduced sensitivity to premiums and an increase in the reward threshold, which is called tolerance. Therefore, there is a repetition and strengthening of addictive behaviors. Specific areas affected within the prefrontal cortex include the dorsolateral prefrontal cortex (DLPFC), responsible for the key components of cognition and executive function (14) and the ventromedial prefrontal cortex (VMPFC) responsible for the components of inhibition and emotional response, which affects the cognitive component of reward processing. The dependent brain enters an "allostatic" state when the reward system is unable to return to its homeostatic (normal) state. The reward system subsequently develops a modified set-point, leaving the individual vulnerable to relapse and addiction. This is what is called the "dark side" of addiction. In the porn addict's brain, brain maps previously established for normal sexuality cannot match the newly developed and continuously strengthened maps generated by watching pornography, and the dependent individual becomes more explicit and the use of graphic pornography to maintain the level higher than excitement. Changes in dopamine receptor density have been implicated in this condition with permanent changes in the reward system. Always recent research has shown that the longer the duration of viewing the pornographic material, the more the volume of gray matter in the right caudate nucleus decreases; moreover, the connectivity between the right caudate and the left dorsolateral prefrontal cortex (DLPFC) decreases, another element of connection with those suffering from behavioral or substance dependence disorder. Finally, other studies have found that the modification of neural structures such as the orbitofrontal cortex (OFC) and subcortical structures are directly linked to the neurochemical changes of serotonin and between serotonin and dopamine. Subjects with excessive viewing of pornography showed impairments in executive functioning believed to involve DLPFC: sexual arousal induced by sexual images has compromised the performance of working and executive memory, also causing attentional disturbances [43].

\section{Clinical treatments}

The disorder, naturally affecting the psychological field, is normally dealt with individual or group psychotherapy, within which a slightly different method is applied than that used in abstinence: a procedure that aims to push the subject to overcome the obsessive perception of the need and return to having a healthy relationship with sexuality. In more complex cases, alongside the cognitive-behavioral or strategic psychotherapy (avoiding the dynamic one, for reasons of duration), anxiolytic drugs and pharmacological therapies capable of attenuating libido can be used, always if there is no need for a targeted drug therapy with antidepressants, mood stabilizers, and antipsychotics in the presence of other psychopathologies, in comorbidity $[5,29,44]$.

The strategic and cognitive-behavioral therapeutic tendencies, in the field of sexual addiction and sexually dysfunctional behaviors, are oriented towards four very specific actions [45].

a) Reduce the sexual drive and hinder the orgasmic cycle; often this goal is sought with the use of antidepressants which, if on the one hand they can reduce active desire, urgency, excitability and lengthen the time for orgasm, they can also instead increase impulsiveness and sexual thoughts, creating a worst addiction condition;

b) Reduce general impulsivity through stabilizers and antidepressants, reducing the duration, extent, and severity of manic episodes;

c) Increase internal gratification, to make the urge to seek more urgent and less frequent, at least in the absence of greater stimuli;

d) Interfere with orgasm to make the pleasure less intense overtime in its final part. 
In Italy, Cantelmi and Lambiase [46], have focused therapy on the motivational interview and the recovery of the patient's metacognitive functions. In fact, according to this approach, the excessive focus in the management of the most striking and contingent symptomatology of the implementation of repetitive, compulsive and / or obscene sexual behaviors, risks losing sight of the possibility of framing the disorder in a more enlarged, which includes the symbolic-existential value that sex represents at that moment for the patient. The hypersexuality disorder would, therefore, be linked to the disorganization of the motivational systems that the subject structured in the developmental age from the interaction with his first caregivers. Referring to the studies on motivational systems carried out by Liotti, the authors integrate the theory of the deficit of metacognitive functions by Antonio Semerari into the theory of schemes of internal operating models. These cognitive schemes correspond to the internal operating models already defined by the psychiatrist and psychoanalyst John Bowlby, who recognized how much he found himself in agreement with the studies conducted in Italy by Giovanni Liotti and Vittorio Guidano, although the latter were of cognitive orientation. The motivational patterns identified by Liotti are divided into three evolutionary levels and are feeding, breathing, exploration, predatory sexual coupling for what concerns the lowest level of evolution, the one that guarantees survival. In the second level, the one that concerns the need for social interaction, typical of the human species, Liotti identifies attachment, cooperation between equals, sexual coupling aimed at couple life, social rank; on the third level, the more advanced ones, the symbolic language, the need for knowledge, the need for the attribution of meanings, the search for values. All these motivational drive models are present in each individual, and can be activated or not by the external situation. According to the two authors, the attachment system is heavily involved in the activation of the sexual motivational system in patients suffering from hypersexuality disorder. Normally, the activation of the first should exclude the activation of the other, as belonging to two different reasons and purposes. However, the two clinicians observed that in patients who are addicted to hypersexuality, sexual behavior was often activated in times of anxiety, fear, or frustration as a tool for managing negative emotions. This is because the carer from whom to receive comfort is not (emotionally) available, the individual has unconsciously "learned" how to achieve emotions of well-being and positive excitement through the sexual act and orgasm. This is confirmed by the numerous studies that correlate the addiction disorder with the incidence of strong previous traumatic experiences. Since this mechanism occurs unconsciously in the patient, he cannot understand and break the automatism that leads him to reiterate sexual behavior in inconvenient situations. Cantelmi and Lambiase believe that the lack of elaboration at a conscious level of the pathogenic process is caused by a deficit in the patient's metacognitive functions, that is, in his ability to reflect on himself, recognize his emotions, modulate them consistently to achieve his goals, put strategies are in place to effectively regulate them. Metacognitive functions are continuously built and reorganized throughout the life of the individual, starting from his first interactions with the primary caregiver. Through the process of emotional mirroring that the latter performs towards the child, he learns to recognize his own emotions, which at a primordial level distinguishes only in "pleasant" or "unpleasant" sensations, and to recognize those of others. The memory of these emotions experienced in childhood is recorded within the subject's implicit and preverbal memory; the memory traces stored will subsequently be reorganized within the motivational systems, which will guide the individual's behavior when a certain system is activated by the external situation. Summarizing, according to the two Italian clinicians, the mechanism underlying the maintenance of sexual addiction is precisely the activation of the wrong motivational system concerning the request of the environment: when the situation would require the activation of the attachment system, which should activate a series of behaviors aimed at calling a comforting figure, seeking help, or implementing other strategies to autonomously mitigate fear and anxiety, the sexual motivational system is activated, prompting the subject to implement compulsive sexual behavior. Specifically of this theory, however, the practical therapy aims to increase the patient's awareness of the origin of his disorder and the dysfunctional way in which sexual arousal is activated in him to compensate for other functions, such as the management of anguish, boredom, fear of being abandoned. Fundamental in the approach of the two authors is to help the patient recognize which emotions and which situations activate sexual arousal in him, to subsequently be able to elaborate alternative coping strategies together. In addition to the specificity of the trauma, Cantelmi and Lambiase have also found that the lack of a specific life plan can also be a risk factor for the hypersexuality disorder, which in some subjects becomes the only unifying and continuous element of existence.

\section{Conclusions}

The clinical category of "dysfunctional sexual behaviors" embraces a series of pathological hypotheses mainly linked to the symptomatology described in the anamnesis. Thus, hypersexuality can simply be the result of a high level of activation or, grading according to the symptoms, the manifestation of a pathological physical or psychic condition: in the first case we will have to orient ourselves on epileptic, vascular, dementia, tumoral disorders, systemic or neuroendocrine infectives; in the second case, on the other hand, we will have to focus on psychopathological profiles, up to addictions and personality disorders. Neuroscientific investigations also confirm the hypothesis that behind dysfunctional sexual behaviors there is the same mechanism that maintains behavioral and/or substance addictions, with particular attention to the ventral tegmental area, the nucleus accumbens, the amygdala, the basal ganglia, the prefrontal cortex and the cortex orbitofrontal. Beyond the hypotheses related to the involvement of dopamine and serotonin, the hypothesis of the involvement of oxytocin in the reward and satisfaction process appears interesting; however, studies on this hypothesis are still few and the data cannot be considered definitive. In the future, greater attention is expected on the oxytocin hypothesis on the subject of addiction to sex, hypersexuality, and pornography.

Citation: Perrotta G (2020) Dysfunctional sexual behaviors: definition, clinical contexts, neurobiological profiles and treatments. Int J Sex Reprod Health Care 3(1): 


\section{References}

1. Perrotta G (2019) Psicologia clinica. Luxco ed.

2. AA VV (2019) ICD-11, Washington.

3. World Health Organization: WHO, Ginevra.

4. Kraus SW, Krueger RB, Briken P, First MB, Stein DJ, et al. (2018) Compulsive sexual behaviour disorder in the ICD-11. World Psychiatry 17: 109-110. Link: https://bit.ly/3iwlm35

5. APA, DSM-V, 2013.

6. Perrotta G (2019) Paraphilic disorder: definition, contexts and clinical strategies. Review article, Author. Journal of Addiction Neuro Research 1: 4. Link: https://bit.ly/34iqHHe

7. Walton MT, Bhullar N (2018) The "Msychology" of Hypersexuality: a 40-years-old bisexual man's use of online chat, pornography, masturbation and extradyadic sex. Archives of Sexual Behaviour 47: 2185-2189. Link: https://bit.ly/34nP9Y2

8. Gwinn AM, Lambert NM, Fincham FD, Maner JK (2013) Pornography, Relationship Alternatives, and Intimate Extradyadic Behavior. Social Psychological and Personality Science 4. Link: https://bit.ly/36z2zCX

9. Brancato G (2014) Psicologia dinamica. Psicoed.

10. Kandel ER (2014) Principi di Neuroscienze, IV ed. IT, Casa Editrice Ambrosiana. Link: https://bit.ly/36xF7Gv

11. Gola M, Draps M (2018) Ventral Striatal Reactivity in Compulsive Sexua Behaviors. Front Psychiatry 9: 546. Link: https://bit.ly/36vNwdh

12. Asiff M, Sidi H, Masiran R, Kumar J, Das S, et al. (2018) Hypersexuality as a neuropsychiatric disorder: the neurobiology and treatment options. Curr Drug Targets 19: 1391-1401. Link: https://bit.ly/30ygN3q

13. De Sousa SMC, Baranoff J, Rushworth LR, Butler J, Sorbello J, et al. (2020) Impulse Control Disorders in Dopamine Agonist-Treated Hyperprolactinemia: Prevalence and Risk Factors. J Clin Endocrinol Metab 105.pii: dgz076. https:// bit.ly/36v5Lja

14. Barake M, Klibanski A, Tritos NA (2018) Management of endocrine disease: Impulse control disorders in patients with hyperpolactinemia treated with dopamine agonists: how much should we worry? Eur J Endocrinol 179 R287-R296. Link: https://bit.ly/33wMcoG

15. Hammes J, Theis H, Giehl K, Hoenig MC, Greuel A, et al. (2019) Dopamine metabolism of the nucleus accumbens and fronto-striatal connectivity modulate impulse control. Brain 142: 733-743. Link: https://bit.ly/33vUKfG

16. Mouly C, Borson-Chazot F, Caron P (2017) L'hypophyse et ses traitements: comment peuvent-ils influer sur le comportement?: The pituitary and its treatments: how can they influence behaviour? Ann Endocrinol (Paris) 78 : S41-S49. Link: https://bit.ly/30ADS5p

17. Guay DR (2019) Drug treatment of paraphilic and nonparaphilic sexual disorders. Clin Ther 31: 1-31. Link: https://bit.ly/34tlHja

18. Boström AE, Chatzittofis A, Ciuculete DM, Flanagan JN, Krattinger R, et al (2020) Hypermethylation-associated downregulation of microRNA-4456 in hypersexual disorder with putative influence on oxytocin signalling: A DNA methylation analysis of miRNA genes. Epigenetics 15: 145-160. Link: https:// pubmed.ncbi.nlm.nih.gov/31542994/

19. Perrotta G (2020) Oxytocin and the role of regulator of emotions: definition, neurobiochemical and clinical contexts, practical applications and contraindications. Archives of Depression and Anxiety 6: 001-005. Link: https://www.peertechz.com/articles/ADA-6-143.php

20. Gündüz N, Turan H, Polat A (2019) Hypersexuality Manifesting as Excessive
Masturbation in a Female Patient After Temporal Lobe Epileptic Surgery: A Rare Case Report. Noro Psikiyatr Ars 56: 316-318. Link: https://bit.ly/3jxOHwu

21. Rathore C, Henning OJ, Luef G, Radhakrishnan K (2019) Sexual dysfunction in people with epilepsy. Epilepsy Behav 100: 106495. Link: https://bit.ly/3jzP3CT

22. Chapman KR, Spitznagel MB (2019) Measurement of sexual disinhibition in dementia: A systematic review. Int J Geriatr Psychiatry 34: 1747-1757. Link: https://bit.ly/3izM77U

23. Nordvig AS, Goldberg DJ, Huey ED, Miller BL (2019) The cognitive aspects of sexual intimacy in dementia patients: a neurophysiological review. Neurocase 25: 66-74. Link: https://bit.ly/2Sudl5r

24. Fuss J, Briken P, Stein DJ, Lochner C (2019) Compulsive sexual behavio disorder in obsessive-compulsive disorder: Prevalence and associated comorbidity. J Behav Addict 8: 242-248. Link: https://bit.ly/3cXteL0

25. Bőthe B, Koós M, Tóth-Király I, Orosz G, Demetrovics Z (2019) Investigating the Associations Of Adult ADHD Symptoms, Hypersexuality, and Problematic Pornography Use Among Men and Women on a Largescale, Non-Clinical Sample. J Sex Med 16: 489-499. Link: https://bit.ly/2StOsqC

26. Garcia-Ruiz PJ (2018) Impulse Control Disorders and Dopamine-Related Creativity: Pathogenesis and Mechanism, Short Review, and Hypothesis. Front Neurol 9: 1041. Link: https://bit.ly/2SpWOzc

27. Castellini G, Rellini AH, Appignanesi C, Pinucci I, Fattorini M, et al. (2018) Deviance or Normalcy? The Relationship Between Paraphilic Thoughts and Behaviors, Hypersexuality, and Psychopathology in a Sample of University Students. J Sex Med 15: 1824-1825. Link: https://bit.ly/36yXPxk

28. Jarial KDS, Purkayastha M, Dutta P, Mukherjee KK, Bhansali A (2018) Hypersexuality following anterior communicating artery aneurysm rupture. Neurol India 66: 868-871. Link: https://bit.ly/3lbQrMr

29. Boccadoro L (1996) SESAMO: Sexuality Evaluation Schedule Assessment Monitoring, Approccio differenziale al profilo idiografico psicosessuale $e$ socioaffettivo. O.S. Organizzazioni Speciali, Firenze.

30. Perrotta G (2019) Psicologia generale. Luxco ed.

31. Sarkis SA (2014) ADHD and Sex: An Interview With Ari Tuckman, su psychologytoday.com, Psychology Today. Link: https://bit.ly/2HYlvB5

32. Park BY, Wilson G, Berger J, Christman M, Reina B, et al. (2016) Is Is Internet Pornography Causing Sexual Dysfunctions? A Review with Clinical Reports. Behav Sci (Basel); 6: 17. Link: https://bit.ly/3jwzgod

33. Porto R (2016) Habitudes masturbatoires et dysfonctions sexuelles masculines. Sexologies 25: 160-165. Link: https://bit.ly/3daPXUd

34. Bőthe B, Tóth-Király I, Potenza MN, Griffiths MD, Orosz G, et al. (2019) Revisiting the Role of Impulsivity and Compulsivity in Problematic Sexual Behaviors. Journal of sex Research 56: 166-179. Link: https://bit.ly/30wCZuC

35. Gola M, Draps M (2018) Ventral striatal reactivity in compulsive sexual behaviours. Frontiers in Psychiatry 9: 546. Link: https://bit.ly/33xFizl

36. Volkow ND, Koob GF, McLellan T (2016) Neurobiologic advances from the brain disease model of addiction. The New England Journal of Medicine 374: 363-371. Link: https://bit.ly/3iwsf5J

37. Miner MH, Raymond N, Mueller BA, Lloyd M, Lim KO (2009) Preliminary investigation of the impulsive and neuroanatomical characteristics of compulsive sexual behavior. Psychiatry Res 174: 146-151. Link https://bit.ly/34nPJFc

38. Kuhn S, Gallinat J (2014) Brain Structure and Functional Connectivity Associated With Pornography Consumption. The Brain on Porn JAMA Psychiatry 71: 827-834. Link: https://bit.ly/2GhtSaw

39. Voon V, Mole TB, Banca P, Porter L, Morris L, et al. (2014) Neural correlates

Citation: Perrotta G (2020) Dysfunctional sexual behaviors: definition, clinical contexts, neurobiological profiles and treatments. Int J Sex Reprod Health Care 3(1): 061-069. DOI: https://dx.doi.org/10.17352/ijsrhc.000015 
of sexual cue reactivity in individuals with and without compulsive sexual behaviours. PLoS One 9: e102419. Link: https://bit.ly/36wUWwZ

40. Doran K, Price J (2014) Pornography and Marriage. Journal of Family and Ecomomic Issues 35: 489-498. Link: https://bit.ly/3iwsOwn

41. Bergner RM, Bridges AJ (2002) The significance of heavy pornography involvement for romantic partners: Research and clinical implications. J Sex Marital Ther 28: 193-206. Link: https://bit.ly/2Srwm8v

42. Boies SC, Cooper A, Osborne CS (2014) Variations in internet-related problems and psychosocial functioning in online sexual activities: implications for social and sexual development of young adults. Cyberpsychol Behav 7: 207-230. Link: https://bit.ly/3jıOIO8
43. De Sousa A, Lodha P (2017) Neurobiology of Pornography Addiction - A clinical review. Telangana Journal of Psychiatry 3: 66-70. Link: https://www.tjponline.org/articles/Neurobiology-of-pornography-addiction-aclinical-review/161

44. Perrotta G (2019) Psicologia dinamica. Luxco ed.

45. Boncinelli V, Rossetto M, Veglia F (2018) Sessuologia clinica, Erickson, I ed.

46. Cantelmi T, Lambiase E (2016) An analysis of a Borderline Personality Disorder case with compulsive sexual perversions according to Interpersonal Motivational Systems and Metacognitive functioning models. Modelli della Mente. Link: https://bit.ly/3leQTJI

Discover a bigger Impact and Visibility of your article publication with

\section{Peertechz Publications}

\section{Highlights}

- Signatory publisher of ORCID

* Signatory Publisher of DORA (San Francisco Declaration on Research Assessment)

* Articles archived in worlds' renowned service providers such as Portico, CNKI, AGRIS TDNet, Base (Bielefeld University Library), CrossRef, Scilit, J-Gate etc.

* Journals indexed in ICMJE, SHERPA/ROMEO, Google Scholar etc.

* OAI-PMH (Open Archives Initiative Protocol for Metadata Harvesting)

* Dedicated Editorial Board for every journal

* Accurate and rapid peer-review process

* Increased citations of published articles through promotions

* Reduced timeline for article publication

Submit your articles and experience a new surge in publication services (https://www.peertechz.com/submission).

Peertechz journals wishes everlasting success in your every endeavours.

Copyright: @ 2020 Perrotta G. This is an open-access article distributed under the terms of the Creative Commons Attribution License, which permits unrestricted use distribution, and reproduction in any medium, provided the original author and source are credited.

Citation: Perrotta G (2020) Dysfunctional sexual behaviors: definition, clinical contexts, neurobiological profiles and treatments. Int J Sex Reprod Health Care 3(1): 061-069. DOI: https://dx.doi.org/10.17352/ijsrhc.000015 